\title{
DISCUSSION
}

This department has been established by the editors in order to afford to those interested in questions relating to economic geology an opportunity for informal discussion. Contributions are cordially invited either in the form of discussion of papers appearing in earlier numbers or bearing upon matters not previously treated. Letters should be directed to the Editor, South Bethlehem, Penna. The full name of the author should be attached to all communications.

\section{HOW SHOULD FAULTS BE NAMED AND CLASSIFIED?}

Sir:-I should like to correct Professor Jaggar's impression that in my text-book, "Geology Applied to Mining," I have confused the distinction between the vertical displacement of a fault and the displacement as measured on the fault plane. I am surprised at this mistake, since for ten years my publications on the subject have been very explicit on the matter of the necessity of not confounding these or other fault functions and nowhere have I expressed this more clearly than in the text-book quoted. Moreover, the quotation given by Professor Jaggar is abbreviated so that the statement contained is quite incorrect, as anyone can see by referring to the original (p. I59). In this textbook and in earlier publications I defined the displacement of a fault as seen in the vertical section and measured along the fault plane as throw. My reason for adopting this definition is shown from the following quotation from my Aspen report:

"It is sometimes possible to find out the amount and direction of movement immediately; but more often it must be indirectly calculated, and to do this it is important to have clearly in mind the nature and value of some of the principal functions of a fault movement, and to have specific terms by which to designate them. The terms already in use are of a rather vague and general character, resulting from the usual conception of a fault as a dislocation of strata. The four terms generally employed are displacement, throw, heave, and offset. The words displacement and throw are 
used interchangeably, and commonly refer to the separation of beds by a fault as seen in a vertical section. Each of these terms is used by some to indicate the distance along the fault plane between the broken ends of the bed as seen in the section, and sometimes the perpendicular distance between the parts of such beds, projected if necessary. There is no agreement, however, which definitely assigns the terms to separate measurements, and indeed it is very common for a writer to use the terms interchangeably for one or the other function. Heave and offset are also used interchangeably, and are usually held to signify the perpendicular distance measured on a horizontal plane, such as the earth's surface, between portions-projected if necessary-of a bed separated by a fault.

"In mining work it is generally necessary to differentiate clearly the different functions of a fault movement, and I have adopted the following terms descriptive of the most important of these. These terms include nothing very novel in the way of nomenclature, but are intended simply to affix definite names to different things."

The different definitions adopted may be seen by referring to the monograph quoted or to the text-book in which they were repeated. There are many other fault functions other than those I have noted; but in these writings I considered that it would be superfluous to do more than point out the principles and to define what I considered the chief functions. Among the additional functions is that referred to by Professor Jaggar as throw and as used by him referring to the vertical displacement. In my system of nomenclature I have reserved the term vertical displacement for this function and have used this term in my work, though I have not included it specifically in the essay above quoted.

Concerning the main question raised by Dr. Ransome as to the retention and definition of the terms "reversed" and " normal" as applied to faulting, I can do no better than quote my definition in "Geology Applied to Mining," which I still hold :

"Most fault planes have an inclination or dip between the horizontal and vertical. When the rocks on the upper side have moved down, relative to the rock on the under side, the fault is called normal. If the reverse movement has taken place, the fault is called a reversed or thrust fault."

This definition takes cognizance only of the actual movement of one rock block, considered as if homogeneous, upon another, and does not take note of apparent geometrical complications 
introduced by stratification or other elements disturbing homogeneity.

The terms "normal" and "reversed" are ancient, have a descriptive value, and I think should not be wholly discarded. According to my idea a fault movement along a strictly vertical plane or along a truly horizontal plane could not be described by either of the terms in question, but a fault along a plane having a dip between the horizontal and the vertical may be called normal if the upper side has moved downward relative to the lower side, and this would hold whatever the direction of the movement might be, provided it was not horizontal. Again, a fault where the upper side has moved down, at whatever angle, may be called reversed. But if along such an inclined fault plane the movement has been horizontal, then again the displacement cannot be included by either of the terms in question and must be described by a composite term.

J. E. SPURR.

Sir:-The current English nomenclature for faults has regarded displacements with reference to the vertical plane. The late Californian earthquake emphasizes the previously recognized fact of displacement in horizontal plane. As the shifting along stratigraphic planes is less apparent or even obscure it is probable that such dislocations will be found to be much more frequent than has been supposed; and in some regions may be the prevailing form. The necessity for recognition and discrimination in our terminology of the horizontal movement is evident. It may be desirable to restrict the old term "fault" to its commonly accepted implication, that is, to the dislocations involved in vertical movements, and to select some new term, like "shift," to express the horizontal or strata-plane displacements.

It is possible that the genetic distinction of "tension" and "compression" may be applicable to shifts as well as to faults; but the structural discrimination of "drop" (gravity) and "thrust" are clearly inapplicable. 
The terms "normal" and "reverse" lack significance as regards both genesis and structure, and are misleading to students. The terms "tension" and "compression" are excellent in the philosophic discussion of the involved forces, though it may be difficult to apply them in specific cases. In description of structure, or the actual displacement, the terms "drop" or "gravity" faults and "thrust" (overthrust) faults are preferable.

With increasing knowledge of the variety and complexity of crustal displacements the limited nomenclature now in use will become inadequate, and other definitive or qualifying terms will be needed.

The following tabulation of the terms given above is offered as a basis for elaboration:

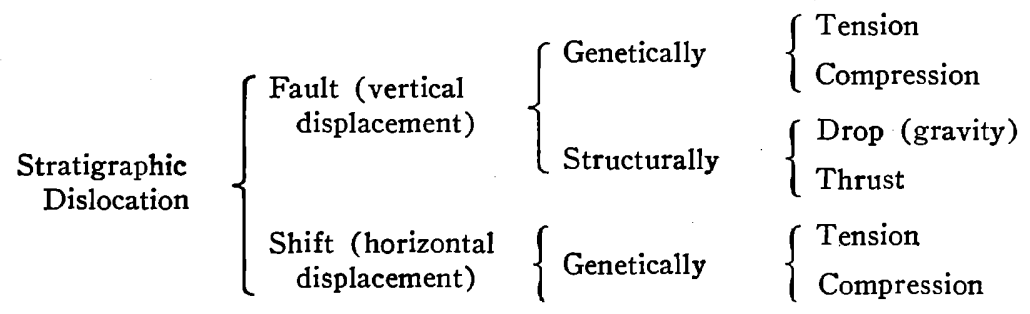

H. L. FAIRChILD. 